\title{
Application of Case-Task Based Approach in Business English Teaching - A Case Study of the Marketing Course in SEIB of GDUFS
}

\author{
Dai Guiyu ${ }^{1} \&$ Cai $\mathrm{Yi}^{1}$ \\ ${ }^{1}$ School of English for International Business, Guangdong University of Foreign Studies, Guangzhou, China \\ Correspondence: Cai Yi, School of English for International Business, Guangdong University of Foreign Studies, \\ Guangzhou, China. E-mail: 20150310030@gdufs.edu.cn
}

Received: November 16, 2016

Accepted: November 30, 2016

Online Published: January 16, 2017

doi:10.5539/hes.v7n1p23

URL: http://dx.doi.org/10.5539/hes.v7n1p23

\begin{abstract}
Business English Teaching aims at cultivating students' ability to analyze and solve problems, improving students' comprehensive language competence and honing their business practical skills. Adhering to the principle of learning by doing and learning by teaching others, Case-Task Based Approach emphasizes students' ability of language use in authentic situation as well as their competence of taking part in social practices, which, to a large extent, corresponds to the objectives of Business English Teaching. Based on a diachronic combing of research ideas of Case-Task Based Approach, this writing analyzes the marketing course offered in School of English for International Business of Guangdong University of Foreign Studies through Case-Task Based Approach, expounds the implementation process of this approach and investigates into its strengths and weaknesses. Finally this writing will have a tentative exploration on how to improve the approach in practice so as to enhance the understanding of its application in Business English Teaching.
\end{abstract}

Keywords: business English, teaching methods, Case-Task based approach

\section{Introduction}

In the 6th National Symposium on English for International Business, Dou (2004) firstly proposed and successfully practiced the idea of combining the strengths of both case study and task-based teaching. He advocates that it is necessary to give full display of the two teaching methods' advantages and break through their limitations, in a hope to really enhance students' all-around English competence. Business English Teaching pays special attention to cultivate students' ability to utilize the knowledge and improve their integrated skills, and especially accentuates the communication skills and teamwork spirits in solving problems. The intended combination of case study and task-based teaching can perfectly meet this objective, making it possible for students to walk more smoothly into the work world after their graduation. However, students and teachers are also confronted with great challenges in the practical use of this combined method and there are many problems remain to be solved.

\section{Literature Review}

Case Study is a teaching method which is based on real career background and aimed to recognize the complexity and ambiguity of the real world through teachers' interpretation and students' discussion. In 1870, Langdell, dean of Harvard Law School, was the first one to systematically apply Case Study in his teaching and the method was well received by the students. This method was not introduced to China until 1980s (Peng, 2012) and was brought into Business English Teaching later on. Wang and Duan's analysis (2010) shows that Case Study puts together professional business knowledge and language skills and simulates the process of real events, thus making language learning more practical and making itself a better learning medium when compared with abstract proposition and concept as well as isolated sentences, discourses and texts. What's more, the teaching process of Case Study has better reflected the teaching ideas of centering on students.

Gong and Luo (2003) puts forward that the core idea of Task-Based Language Teaching (TBLT) is to simulate various language activities people conducted in society or in school life; TBLT segments the actual social activities into several specific "tasks" and takes the cultivation of students' ability to fulfill those tasks as its objective. Its advocates believe that the best way to learn a language is to perform various tasks with language; 
when learners are actively applying the targeted language in communication, the language will be acquired in the process naturally.

To sum up, Case-Study Method (CSM) and Task-based Language Teaching (TBLT) share something in common from the theoretical perspective, for example, both of them fall into the category of Communicative Teaching Method, abide by student-centered language teaching, and emphasize the authenticity of speech and situation. Many scholars have made explorations in this aspect.

However, because Case Study Method (CSM) has an obvious demerit of lacking general explanation of concepts and theories, students cannot have a good control of conceptualized knowledge and thus can not apply it properly. TBLT, which explains the basic theories and concepts at first, can somewhat make up for the deficiency of CSM. Jiang (2006) believes that one of the most distinct characteristics of CSM is that it adopts "tasks"; it includes authentic or almost authentic tasks set in the background of real business situations. Wang and Duan (2010) also believed that CSM is the concrete application of TBLT in Business English Teaching; "case" and "task" are basically the same since cases are composed of various tasks and tasks can be reflected as different cases.

CSM and TBLT are inseparable in practical use, and the combination of these two methods is widely recognized. According to the survey of Wang (2014), CMS is the teaching method most welcomed by students, who hope that they could comprehend and digest business knowledge through concrete business cases (or tasks) in class.

\section{Case-Task Based Approach}

In order to figure out the teaching process of Case-Task Based Approach, this writing will first analyze the teaching process of CSM and TBLT separately.

TBLT will consider three questions when defining teaching activities: 1) how to combine the input of language knowledge with the topic; 2) how to combine the language knowledge accumulation and language skills training with the topic; 3) how to relate the language output with the topic. In this way, the process of TBLT can be summarized as three stages: 1) Pre-Task Preparation; 2) While-Task Process; 3) Post-Task Activity (Luo \& Gong, 2003, p. 82).

In the first stage of Pre-Task Preparation, teachers should provide students with new language materials. When inputting those new materials, teachers should stimulate students' imagination, engage them in divergent thinking and motivate them to associate the knowledge with their life experience, thus establishing a kind of connection between the existed knowledge and the new knowledge so as to enhance comprehension and memorizing. The While-Task Process can be sub-divided into two stages: mechanical practice and meaningful practice. The former mainly trains the basic skills, while the latter aims to transform students' cognition of knowledge from the external characteristics to the internal relation. In the Post-Task Activity, students are asked to fulfill a communicative task with the following features: 1) being in a life simulation of language-use environment; 2) there being information gap between the two sides; 3) solving practical problems; 4) giving full play to students' autonomy and creativity (Luo \& Gong, 2003, p. 88).

The teaching process of CSM also includes three stages: Case Introduction, Problem Presenting, and Problem Analyzing and Solving. Case Introduction requires the comprehensive application of language skills in describing the situation, involving stylistic knowledge and business language such as narration and description. In presenting the problem, students are asked to analyze the problem in connection with real situation, so as to foster their critical thinking and cultivate their wording and phrasing ability. In analyzing and solving the problem, students need to have group discussions to address the problem cooperatively; in this process, their problem-solving ability will somewhat be improved and they will be much in their elements when entering the business world (Chen, 2013, p. 43).

The teaching processes of CSM and TBLT are indicated as follows: 


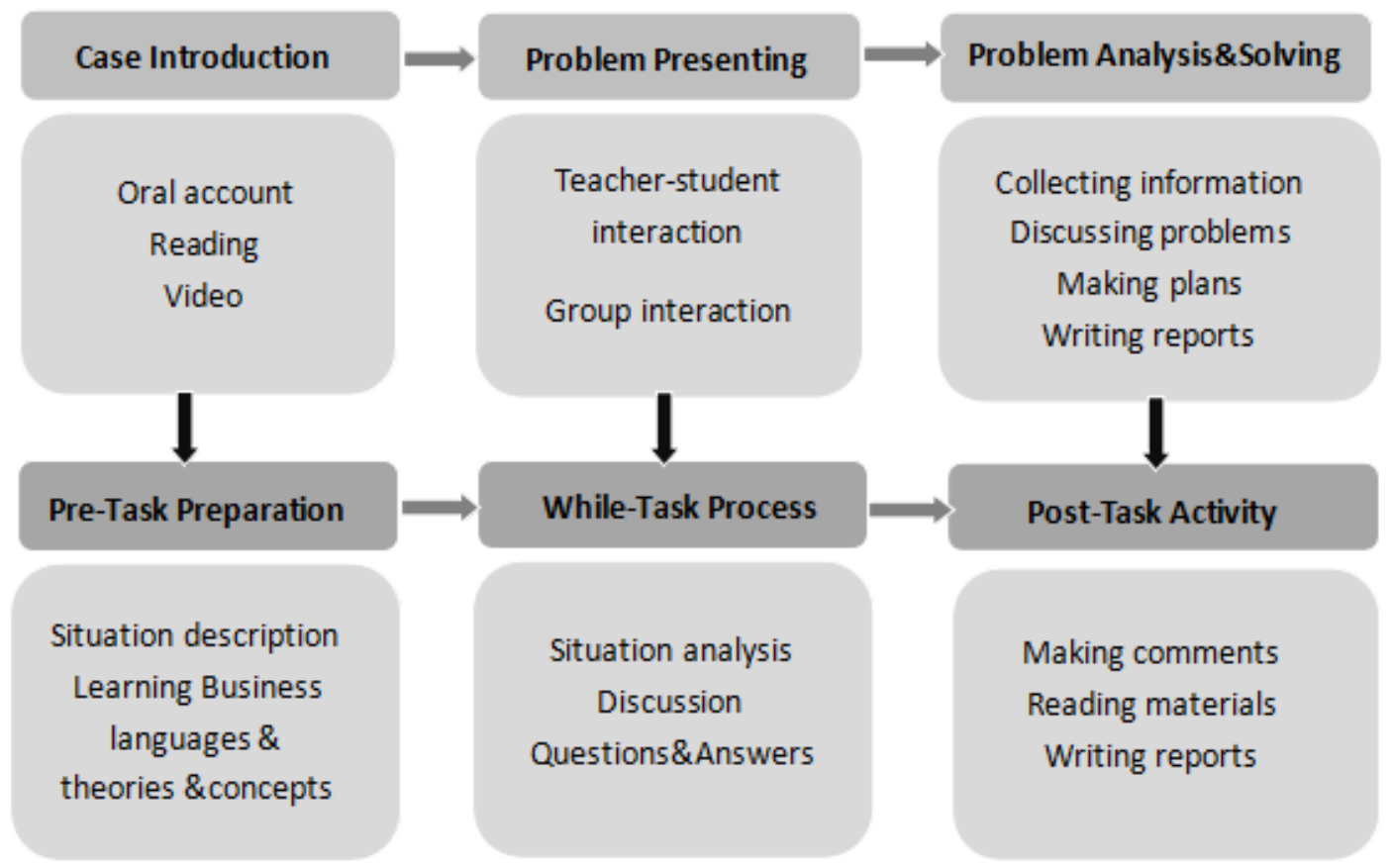

Figure 1. The teaching processes of CSM and TBLT

The flow chart above has integrated the teaching process of CSM and TBLT. As it indicates, each stage of CSM corresponds to one of the three in TBLT. However, in the first stage of TBLT-the Pre-Task Preparation, it is not only an introduction to new cases but also an elucidation of a central topic and relevant concepts and theories, which has made up for the deficient theoretic explanation of CSM. Therefore, Case-Task Based Approach, which synthesizes CSM and TBLT, is more widely applicable. From the above analysis, this writing has a tentative summary of the teaching process of Case-Task Based Approach: 1) Theoretical knowledge preparation; 2) Case preparation; 3) Case analysis; 4) Case presentation; 5) Case summary; 6) Case report writing.

\section{Case Study: The Application of Case-Task Based Approach in the Marketing Course}

This case study takes as the object the marketing course offered in SEIB of GDUFS since it has given full expression to the application of Case-Task Based Approach. In teaching this course, the teacher firstly explains the theories and concepts relating to the topic and then arranges another teaching period (90mins) to conduct the group project in the form of simulating corporate meetings. The project is arranged as follows: students are divided into four groups; in each case analysis, there will be a host group (each group will have the opportunity to be the host group) and three other supporting groups; each project will only assess the host group while the other three are obliged to participate actively. In the following part, this writing will take one case from the class-LivLuv's Channel Issues for Yummy Slurps as an example to analyze the teaching process of Case-Task Based Approach.

\subsection{Theoretical Knowledge Preparation}

In this stage, the teacher firstly introduces the theoretic knowledge. Only by equipping the students with relevant knowledge can they find a connection between the old and the new and through the interaction of which they can finally build their own schemata of knowledge (Peng, 2012, p. 255). When learning and distinguishing relevant concepts, students should also learn how to use English to express certain technical terms and relate Chinese concepts with corresponding English ones. In this stage, the teacher will explain the theories in English with some accessible and understandable examples in everyday life so as to link theory with practice.

Before analyzing the case of LivLuv's Channel Issues for Yummy Slurps, the teacher introduces the main theories and concepts related to Marketing Channels and Supply Chain Management, which goes as follows:

1) Explain why companies use marketing channels and discuss the functions these channels perform; 
2) Discuss how channel members interact and how they organize to perform the work of the channel;

3) Identify the major channel alternatives open to a company;

4) Explain how companies select, motivate, and evaluate channel members;

5) Discuss the nature and importance of marketing logistics and integrated supply chain management.

\subsection{Case Preparation}

After the first step of theoretical knowledge preparation, the teacher will hand out the well-prepared case to students. As CSM indicates, case is the key and core of this teaching method. However, it entails great efforts for the teacher to choose a well-suited one. There being no fixed teaching model of CSM to follow, the teacher should define the subject and scope of the case by himself and control the complexity of the case, leading students into a specific situation in an optimized way and stimulating their curiosity, which will finally be conducive to improve both teacher's and students' performance (Hong, 2016, p. 99).

If the business case is representative, it will be of great help for students who lack business background. However, it requires the teacher to select authentic cases and entwine them with the teaching content. The case that is made up by the teacher is less practical and less compelling (Feng, 2011, p. 580); but if it is authentic, students will involve themselves into the case, which will accordingly drive them to think and reflect (Wang \& Duan, 2010, p. 98). Therefore, it would be better if the case is close to students' daily life. In addition, there are other criteria of choosing a case, for example, the chosen case should be correspondent to the curriculum framework, appropriate in length, interesting to the participants, but not out of date (James, 2011).

In teaching this course, the teacher has chosen some other companies as analytic targets besides LivLuv, such as Costa Coffee, Daiso, Guangzhou Jiumaojiu Restaurant etc. Those companies are accessible to students and are indeed confronted with some problems demanding prompt solution, which makes it possible for the students to obtain necessary information to conduct case analysis and motivate them to figure out the possible solution.

In conclusion, choosing appropriate cases is of great importance to Case-Task Based Approach, and the cases should be authentic, intriguing, reasonable and time-effective.

\subsection{Case Analysis}

In teaching the course, the teacher will hand out the case to students beforehand. The materials for the host group and for the supporting groups are different. Take LivLuv as an example: the host group gets not only the background information, but also that of the participants (refers to the supporting group, each group is assigned 2-3 roles) and also the problems needing to be solved in this conference, while the supporting group gets some other information about their specific roles, particular responsibilities and the potential problems. The case analysis and discussion are conducted within the groups. The host group and the supporting groups are not allowed to exchange information with each other before the official meeting (in the class). Otherwise, the conference simulation will be all set up beforehand, and then there will be no chance to improve students' strain capacity.

The answers to the problems discussed in the case are open. Based on the provided materials, students should gather information through various channels to find out the answers. In this way, students' enthusiasm will be fully mobilized and their learning effect will be obviously increased (Feng, 2011, p. 580). Besides, group discussion will motivate students to have a divergent thinking, and the collision of different ideas may spark some new thoughts. The whole process will help students deepen their understanding of the concepts and theories and cultivate their creative thinking. However, the teacher should supervise the whole discussion process in case of digressing from the topic.

In the discussion, different opinions may confront each other. In order to make themselves understood and accepted, students must learn how to communicate with others and convey their own ideas effectively. As a result, their communicative and expressive skills will be improved and at the same time, they can learn how to listen attentively to and show their respects for others.

When discussing the case of LivLuv, the host group needs to discuss and consider a lot of problems coordinately. The host group is LivLuv Pet Foods' mainland China market's sales management team, and the roles the other three groups play are as follows:

Group 1: Mass Market key account representatives, Professional key account representatives, Online Channel key accounts

Group 2: Other Marketing Intermediaries you have dealt with who facilitate your marketing Programs (...) 


\section{Group 3: Target end-consumer representatives (...)}

This case is mainly about how the management team exchange information with stakeholders and how to surpass rivals with its good quality and relatively high prices. In the meeting, they should negotiate a proper price and figure out channel management strategies, and finally reach a consensus on future cooperation.

Being unable to communicate with supporting groups in advance, the host group must conceive all the possible questions that could be asked and seek a way to manage the channel, making sure that the products can be introduced to market successfully. For example, the online channels can promote the products by designing the marketing mix or providing seasonal discount.

In conclusion, during the case analysis, students can learn how to express themselves with proper language and how to be a good listener; therefore, their communication skills can be improved in an all-round way.

\subsection{Case Presentation}

Presenting the case here is in the form of official meeting. Led by the host group, each role from each group has its say in this meeting and the discussion will center on the problems to be solved. Since the materials provided to the host group and the supporting groups are different, there exists information gap between two sides, which makes it necessary to communicate.

Language activities should engage learners in the meaningful and actual language use rather than the mechanical practice of language structures. The language use (communication) should be "meaningful", indicating that the language teaching should simulate the psychological process of a person in language activities. Each and every psychological process begins with the motivation of conveying information, and its essential mechanism is information gap. Only with information gap will the language be meaningful and the communication is necessary; and only by this means will students gain psychological experience of communication and acquire communicative competence (Wang \& Duan, 2010, p. 98).

Under the guidance of the host group, all the problems that have been discussed will be presented in the meeting. To fill the information gap and reach a consensus within groups makes the communication meaningful and this process improve students' practical ability as well as their ability to use knowledge.

\subsection{Case Summary}

The essence of CSM lies in how to apply the theory already learned in the case analysis and find out the possible solution. After the case presentation, teacher should point out the important points in the case as well as the achievements and limitations of the case presentation. In addition, to ensure students' participation, there should be a set of criteria to assess students' performance which will finally be quantified into scores (Feng, 2011, p. 580).

In summarizing the LivLuv case, the teacher firstly has a general comment on the whole process, and then points out the major problems existing in the case analysis. What's more, the whole class is required to score the host group according to certain predetermined criteria: 1) whether the goal of the meeting is achieved; 2) whether the host group is convincing; 3 ) whether the meeting has met your expectancy; 4) whether the meeting will influence your decision, etc. If time is sufficient, the teacher will ask some students to make a short comments on the whole meeting and invite suggestions from them.

\subsection{Case Report Writing}

In the end, the host group needs to write an English report to analyze the case and put forward some possible solutions. In writing the report on LivLuv, the host group needs to analyze each and every stakeholders of the company, explaining how to cooperate with them to manage the marketing channels and fix the product prices for the purpose of maximizing the market shares. The most important point in this report is the marketing decision they made after the meeting. In order to substantiate the report and make it more convincing, it would be necessary to provide some data and examples and record the questions and answers from both sides in the meeting.

The students will encounter lots of problems in writing the report, for example, how to handle the details in the meeting, how to make the report more logically clear, etc. The teacher should guide students and familiarize them with the format of writing a report. Before writing a report, the students need to gather and evaluate literature information, which will lay a solid foundation for writing academic papers. 


\section{The Advantages and Problems of Case-Task Based Approach}

Through the analysis of Case-Task Based Approach in the Marketing Course, we find that the approach itself has its advantages though there remain some problems to be solved.

The advantages of Case-Task Based Approach can be summarized as follows: 1) it can effectively improve students' communication skills and their ability to use knowledge; 2) it trains students to be a good listener and team player; 3 ) it bridges the gap between the theory and the practice, etc. The classroom activities based on real-life situation can build students' confidence and make them well-prepared when stepping into the business world (Gong, 2009, p. 148). Besides, exposing students to the real business environment will motivate them to analyze and solve problems, and can encourage them to work hard to acquire knowledge and hone their skills (Jiang, 2006, p. 58).

However, in the application of Case-Task Based Approach, there exist some concrete problems as showed in the following aspects:

\section{1) In aspect of students}

Case-Task Based Approach has a high demand of students' comprehensive capacity. As English is the classroom language, it requires students to be quite proficient at English so as to follow the teacher, or else it would be rather difficult to understand some basic concepts and theories, let alone to put the theory into practice. Sometimes the teacher's intention is quite elusive and the case provided is too professional to understand, so the case presentation could be a far cry from teacher's expectancy.

2) In the aspect of teachers

Teachers have to attend to many difficulties in the teaching, such as choosing appropriate cases, using professional business language, making elusive theories easy understood (Chen, 2013, p. 44). Case-Task Based Approach requires a lot on the choosing and compiling of the cases. Teachers should not only consider students existing level of knowledge and language, but should also meet their demand and arouse their interests. In case presentation, teachers should have a holistic control over the discussion and ensure that it will progress smoothly. In the end of discussion, teachers should make a penetrating comments and incisive conclusion, ensuring that students could have a clear realization of their own performance.

However, in the class of the marketing course, we find that though the teacher spares no efforts to make the course interesting and instructive, not all the students accept and appreciate it. The problems are mainly reflected in the following aspects: 1) the teacher has overestimated students' language proficiency - the teacher speaks English too fast and students find it difficult to catch up, thus there are some problems in understanding the basic concepts; 2) the teacher offers students the cases with no further explanation, and students are confused about what to do and may digress from the topic; 3) when students do not live up to the teacher's expectancy, the teacher would appear to be very disappointed, which has greatly spoiled students' enthusiasm.

In order to solve the problems existing in Case-Task Based Approach, both technical measures and non-technical measures should be taken. On the technical level, students should improve their language skills and be well-prepared before the class (such as reading relevant Chinese materials to improve comprehension); teachers should optimize the design of the cases in practice, making it more accessible and less intimidating. On the non-technical level, students and teachers should enhance communication. Students should reflect to teachers in time when they have confusions; teachers should explain to students the objectives of Case-Task Based Approach as well as the way to conduct case analysis; teachers should also encourage students and boost their confidence, making them realized that case analysis is a critical thinking training-oriented activity rather than an answer-oriented activity (Dou, 2004, p. 21).

\section{Conclusion}

Case-Task Based Approach is a comprehensive and innovative application of Case-Study Method and Task-Based Language Teaching. Task-Based Language Teaching involves three stages: 1) Pre-Task Preparation; 2) While-Task Process; 3) Post-Task Activity. Case-Study Method also entails three stages, that is, Case Introduction, Problem Presenting, and Problem Analyzing and Solving. Both of them fall into the category of Communicative Teaching Method. The combination of these two methods has made up for the deficiencies of each other. Based on previous study, this writing has a tentative summary of the teaching process of Case-Task Based Approach: 1) Theoretical knowledge preparation; 2) Cases preparation; 3) Case analysis; 4) Case presentation; 5) Case summary; 6) Case report writing, and then takes the marketing course offered in SEIB of GDUFS as an example to analyze that process as well as the strengths and weaknesses of this method. The problem of Case-Task Based Approach mainly lies in that the students' language proficiency is hard to predict 
and the complexity of the case is hard to control. As a result, the students should improve their language skills, the teachers should optimize the cases and the students and teachers should enhance mutual communication to achieve better teaching results.

\section{References}

Chen, D. C. (2013). Research on Business-based College English Teaching Model of Practical Language Skills. Foreign Language World, 4, 40-47.

Chen, J. P. (2004). Case Study Method and Business English Teaching. Journal of Ningbo University, 26(5), $113-115$.

Dou, W. L. (2004). Innovating Teaching Method and Exploring the Successful model to Improve Students' All-round English Competence: The Application of Case-Task Method in Business English Teaching. In The 6th National Symposium on English for International Business. Changsha, Hunan.

Feng, J. (2011). The Application of Case Study Method in Business English Teaching. Jiangxi Agricultural University (Social Science Edition), 6, 579-581.

Gong, H. (2009). Case Study Method in Business English Teaching. Science and Technology Innovation Herald, $2,148$.

Gong, Y. F., \& Luo, S. Q. (2003). Task-Based Language Teaching. Beijing: People's Education Press.

Hong, Y., \& Zhang, T. J. (2016). An Analysis of the Application of Case Study Method in Business English Teaching. Journal of Harbin Finance University, 1, 98-100.

James, A. E., Michiel, R. L., \& Louise, A. M. L. (2011). Teaching with Cases. Beijing: Beijing Normal University Press.

Jiang, X. J. (2006). Case Study and Business English. International Business Study, 6, 57-60.

Peng, J. G. (2012). An Analysis of Case Study in Business English Teaching. Economic Research Guide, 8, 253-255.

Wang, L. N., \& Duan, J. (2010). The Case-Study Method in Business English Teaching. Foreign Language and Literature, 26(4), 96-100.

Wang, Y. Y., Wang, G. L., \& Deng, L. N. (2014). Research on the Demand of Business Talents and Talents Training Model. Foreign Language World, 2, 34-41.

\section{Copyrights}

Copyright for this article is retained by the author(s), with first publication rights granted to the journal.

This is an open-access article distributed under the terms and conditions of the Creative Commons Attribution license (http://creativecommons.org/licenses/by/4.0/). 